\title{
Crack Detection on Metal Surfaces with an Array of Complementary Split Ring Resonators
}

\author{
Rajni \\ Associate Professor \\ Department of ECE, SBSSTC \\ Ferozepur, Punjab, India
}

\author{
Amanpreet Kaur \\ Research scholar \\ Department of ECE, SBSSTC \\ Ferozepur, Punjab, India
}

\author{
Anupma Marwaha \\ Associate Professor \\ Department of ECE, SLIET \\ Longowal, Punjab, India
}

\begin{abstract}
In this paper, an advanced sensor based on an array of Complementary Split Ring Resonators (CSRRs) has been presented for detecting metal fatigue, operating around at 10 GHz. The scanning mechanism of advanced sensor is based on perturbing the electromagnetic field in the vicinity of a negative effective dielectric permittivity, thus causing a large shift in resonant frequency. A metal fatigue is detected by using a periodic structure of CSRRs - a concept introduced here for first time-etched on ground plane. The electric field generated by the current on metal surface affects the transmission coefficient due to variation in lumped parameters of CSRR and leads to high sensitivity in detecting anomalies such as cracks in the Surface. The electromagnetic interaction of CSRR with small sized crack is analyzed with electromagnetic solver. In this paper, the shifting of transmission coefficient is observed by varying the width of the crack in the range of $25 \mu \mathrm{m}-200 \mu \mathrm{m}$. The simulated results show the feasibility of detecting very small cracks such as $25 \mu \mathrm{m}$ crack width, in the metallic surfaces.
\end{abstract}

\section{Keywords}

Complementary Split Ring Resonators, Crack, Microstrip line, Metamaterial

\section{INTRODUCTION}

Cyclic loading of mechanical components leads to the development and growth of fatigue cracks on the metallic surface. Hidden cracks in structural units results in fracture and adversely damage the structure. So, inspection of fatigue cracks becomes essential especially in aircraft fuselage, wire ropes used in lifting devices and railway tracks. Several electromagnetic nondestructive testing techniques had been used for detecting surface cracks in metallic surfaces, each of which were having certain constraints and disadvantages [1]. These limitations were overcome with the introduction of microwave and millimeter technology technique [2-4]. In [2], the microwave technique is based on using an open-ended waveguide to detect long cracks in metal surface. The presence of a crack on the surface of the metal disturbs the near-field distribution at the end of the waveguide causes a change in the reflection coefficient that is recorded with a diode detector. However, with the aforementioned technique the operating frequency is around $20 \mathrm{GHz}$ due to which the cost of associated circuit and setup increases. So, in [5] a Single complementary split ring resonator etched out from ground plane of microstrip line was used to detect crack of $100 \mu \mathrm{m}$, operating around $5 \mathrm{GHz}$. This technique has distinct merits over microwave and millimeter technology techniques used previously. This same setup was further modified, instead of single CSRR few are etched out from ground plane thus forming a periodic structure of CSRRs.
The periodic structure of CSRRs is already used in filter designing, where it serves the purpose of improving filter characteristics and suppression of side lobes as in [6]. Mostly, CSRR's have been commonly employed for the purpose of miniaturization. So, this paper looks forward for some innovative use of the CSRR structure rather than employing it for antennas miniaturization or in any filter application. The single unit of CSRR has already been used for crack detection in [5]. Till date an array of CSRR etched from the ground plane of microstrip line has not been used for detection of fatigue crack on metal surface. Through this work a lime light is thrown on the use of an array of CSRRs for the detection of crack. However, the periodic structure of SRRs loaded with waveguide probe have been employed for the same purpose leading to high sensitivity in detection of anomalies such as cracks [7]. A similar response is observed employing a periodic structure of CSRRs etched out from the ground of a microstrip line. In this paper, a background of the work done in the area explored is given in Section 1. Section 2 presents the design and equivalent circuit of CSRR. Section 3 presents the design of proposed sensor. Section 4 gives result and discussion followed by final conclusions of work in Section 5 .

\section{COMPLEMENTARY SPLIT RING RESONATOR}

CSRR and SRR are component particles for exotic materials known as 'Metamaterials'. CSRR are derived from the SRR structure in a straightforward way by using the concepts of duality and complementariness [8]. CSRRs are called sublambda structures because of small size. The SRR possessing negative permeability behaves as a magnetic dipole whereas CSRR behaves as an electric dipole possessing negative permittivity [9-10]. CSRR is excited by an axial electric field. The electric field affects the lumped parameters of CSRR. Whereas, the magnetic flux effects the equivalent lumped parameters of the SRRs. The geometry of CSRR is given in Figure 1(a) and its equivalent circuit model of CSRR is shown in Figure 1(b).

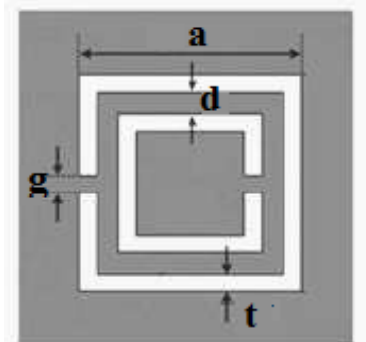

(a)

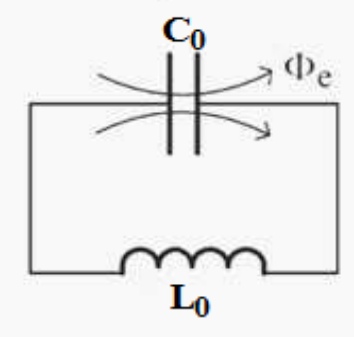

(b)
Figure 1(a) Geometry of CSRR. (b) Its equivalent circuit 
The design equation of CSRR is given in [11-12]. The resonance frequency of the metamaterial structure depends on three variables $a, t, d$. The equivalent inductance, capacitance and resonance frequency are given in equation (1)-(4).

$$
L=\frac{4.86 \mu_{0}}{2}(a-t-d)\left[\ln \left(\frac{0.98}{\rho}+1.84 \rho\right)\right]
$$

Where, $a=$ length of the CSRR

$$
\begin{aligned}
& \mathrm{t}=\text { thickness of CSRR } \\
& \mathrm{d}=\text { spacing between the rings }
\end{aligned}
$$

$\rho=\frac{t+d}{a-t-d}$

$C=(a-1.5(t+d)) C_{p u l}$

Where $C_{\text {pul }}$ is capacitance per unit length between the rings.

The resonant frequency of CSRR structure is formulated as:

$f_{\text {calculated }}=\frac{1}{2 \pi \sqrt{L C}}$

By tuning the CSRR geometry, the capacitance and inductance values can be controlled. Thus, it is assumed that the currents present on metal plate will generate equivalent electric flux for CSRR and affect its lumped parameters. This electric flux gets disturbed in the proximity of resonators and indicates the presence of crack on the metal surface placed underneath the sensor.

\section{PROPOSED MODEL OF CRACK DETECTION}

In this model, a conventional microstrip line is loaded with an array of CSRR. The CSRR is etched below the microstrip line by removal of metal from the ground and the crack is cut from the aluminum plate covered by Teflon film. This advance sensor is modeled on Rogers RO4350 substrate of thickness $0.75 \mathrm{~mm}$, dielectric permittivity $\left(\varepsilon_{\mathrm{r}}\right) 3.48$ and loss tangent 0.0031 . A thin teflon film of $0.0762 \mathrm{~mm}$ is used to conceal the surface of an aluminum plate which possibly hide the crack from visual inspection. The sensing or crack scanning is performed by sliding the sensor above the aluminum metallic plate. In order to excite the CSRR, the microstrip line initiates an electric field orthogonal to the ground plane. When a crack is encountered a change in resonance frequency is examined, which confirms the detection of fatigue crack on metal surface [6].

Figure 2 (a) shows the top view of the periodic structure of CSRRs used to detect the crack of aluminum plate. The crack with height (h), gap (g) and width (w) below the ground is shown in Figure 2 (b).

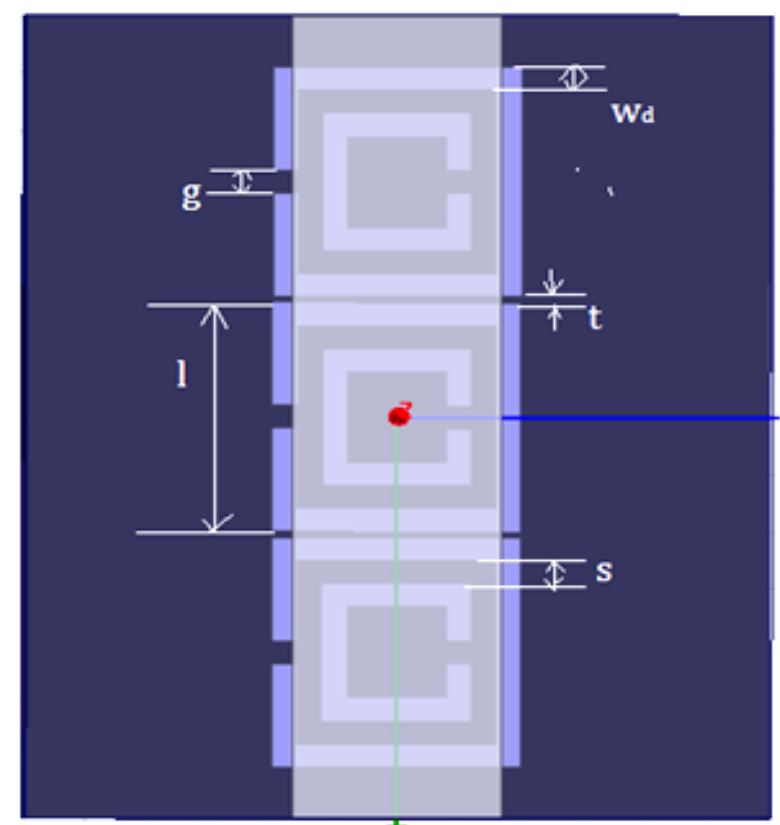

(a)

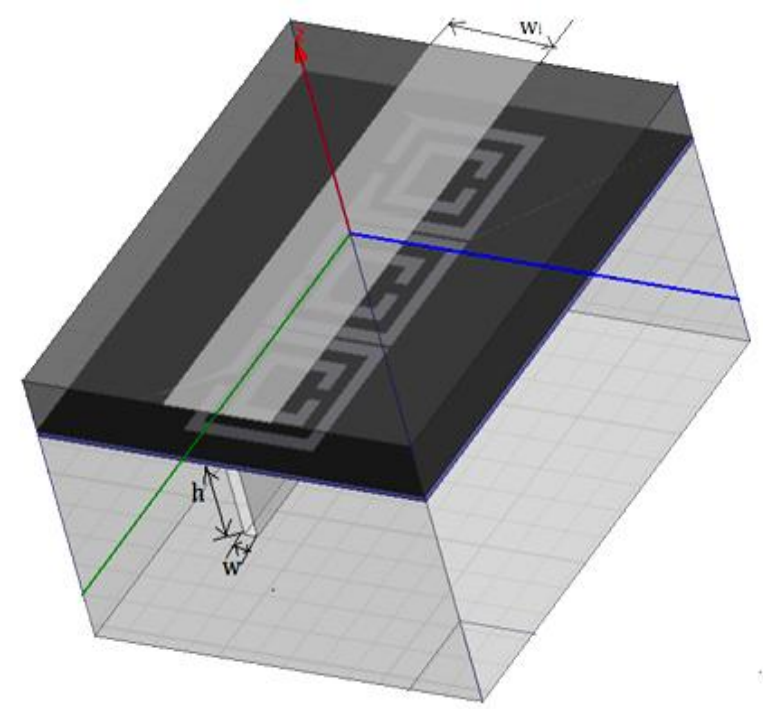

(b)

Figure 2: Crack detected model with array of CSRR (a) Top view of the model; (b) 3-D side view of the model

Figure 2 shows schematic of proposed sensor based on periodic structure of CSRRs for crack detection. The sensor is placed over the metal surface as shown in Figure 2 (b), and any defect in the metal surface will disturb the field around resonator. This disturbance in the field produces variation in the resonance frequency or transmission coefficient. The main emphasizes of this work is to design a sensor in order to achieve resonance frequency close to $10 \mathrm{GHz}$. Obtaining resonance at a precise and distinct frequency is least important here. The dimensions of the model are shown in the table below. Table 1 describes the different parameters, their values and also illustrates that the width of the crack (w) is being varied from $25 \mu \mathrm{m}$ to $200 \mu \mathrm{m}(0.025-0.2 \mathrm{~mm})$ range. 
Table 1. The dimension of the proposed model

\begin{tabular}{|c|c|c|}
\hline Sr. no. & Parameters & Values (in mm) \\
\hline 1 & Length of CSRR, 1 & 2 \\
\hline 2 & Width of CSRR, $\mathrm{w}_{\mathrm{d}}$ & 0.2 \\
\hline 3 & Gap of split of CSRR, $\mathrm{g}$ & 0.2 \\
\hline 4 & $\begin{array}{c}\text { Spacing between inner and } \\
\text { outer SRR, } \mathrm{s}\end{array}$ & 0.05 \\
\hline 5 & $\begin{array}{c}\text { Gap between the arrays of } \\
\text { CSRR, } \mathrm{t}\end{array}$ & 1.2 \\
\hline 6 & Width of microstrip line, $\mathrm{w}_{\mathrm{i}}$ & 1 \\
\hline 7 & Height of crack, $\mathrm{h}$ & $0.025-0.2$ \\
\hline 8 & Width of crack, $\mathrm{w}$ & \\
\hline
\end{tabular}

\section{RESULT AND DISCUSSION}

The Crack detection model employing periodic structure of CSRRs is simulated to attain the desired resonating frequency region. The two wave ports 1 and 2 are assigned to the both sides of microstrip line. Periodic CSRR sensor initiated here is intended to detect the cracks in certain class of media. The main concern lies in the detection of crack in aluminum plates concealed by thin film of teflon. The scanning is performed by moving the sensor above the aluminum plate. As a defect is encountered on the metal plate placed underneath the ground plane of the microstrip line, a change in the resonance frequency is registered for a single CSRR based sensor and variation in transmission coefficient is registered for periodic structure of CSRR. This change is the indication of presence of defects such as cracks on surfaces and examination of sensitivity of the sensor is measured by its ability to detect cracks of small dimensions.

In Figure 3, the variation in the resonant frequency for 100 $\mu \mathrm{m}$ and $200 \mu \mathrm{m}$ widths of a crack) is shown when a sensor employing single CSRR is used, with respect to the reference case (i.e. when there is no crack on metal plate placed under sensor). It is observed from figure that with the presence of crack there is a small shift in the resonating frequency from reference case. This downward shift in the resonance frequency from the reference case is the indication of the presence of crack on metal surface.

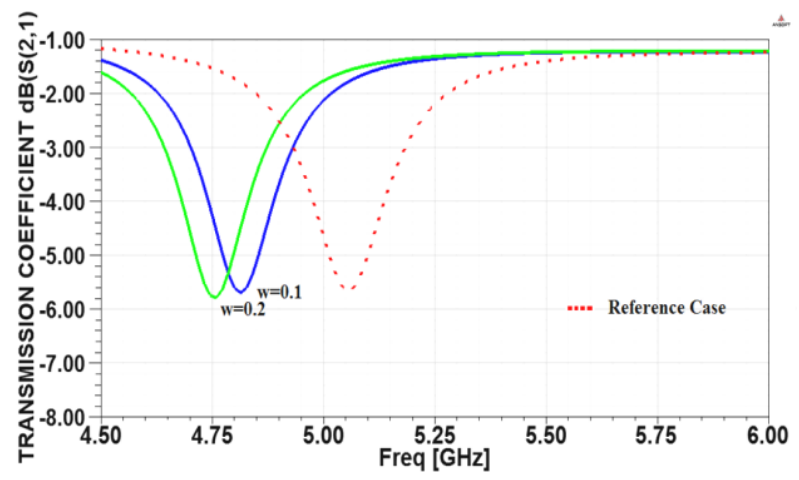

Figure 3: Transmission coefficient $\left(S_{21}\right)$ of sensor based on single CSRR for $100 \mu \mathrm{m}$ and $200 \mu \mathrm{m}$ crack widths
The new proposed sensor employing periodic structure of CSRR is able to detect even the smallest crack as efficiently as it can detect small cracks of $100 \mu \mathrm{m}$ and $200 \mu \mathrm{m}$ widths. Figure 4 presents the resonant frequency of minimum transmission with periodic CSRR structure when a crack of widths $100 \mu \mathrm{m}, 200 \mu \mathrm{m}$ and $1 \mathrm{~mm}$ depth is created on the surface of aluminum plate. The resonance frequency for the both crack widths is same however, a small variation in the transmission coefficient is observed.

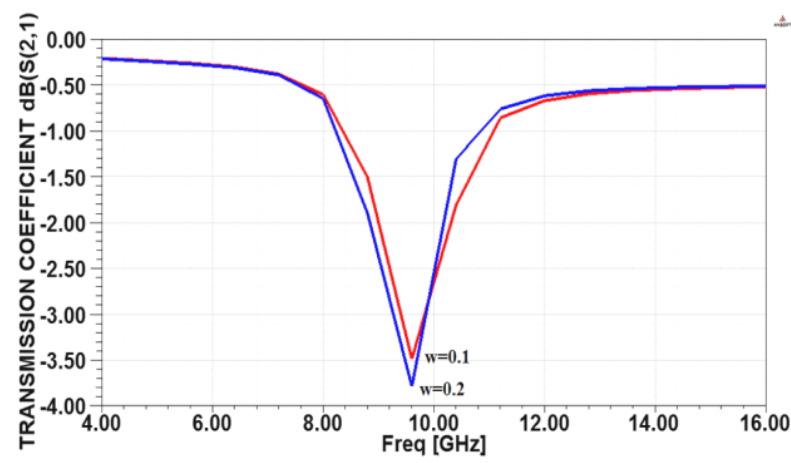

Figure 4: Transmission coefficient $\left(S_{21}\right)$ of sensor based on periodic CSRR for $100 \mu \mathrm{m}$ and $200 \mu \mathrm{m}$ crack widths

The working of the proposed sensor is better than already existing sensors that employ a single CSRR for the same task. A large shift about two times in the resonant frequency is registered with the new sensor design. The resonant frequency of the proposed sensor is around $10 \mathrm{GHz}$ which is approximately twice that of sensor with a single CSRR operating around $5 \mathrm{GHz}$ as shown in Figure 3.This large shift enhances the sensitivity of the sensor. Due to which the sensor is very efficient to detect very narrow cracks of width $25 \mu \mathrm{m}$ $75 \mu \mathrm{m}$, varying with step size of 25 with precision. The variation in transmission coefficient is being registered while the resonant frequency remains same for various crack widths as illustrated in Figure 5. The transmission minimum frequency for single CSRR and periodic CSRR is given in table 2.This large shift enhances the sensor ability to easily detect even small cracks very efficiently. From which it is concluded that periodic sensor exhibits high sensitivity in detection of fatigue cracks.

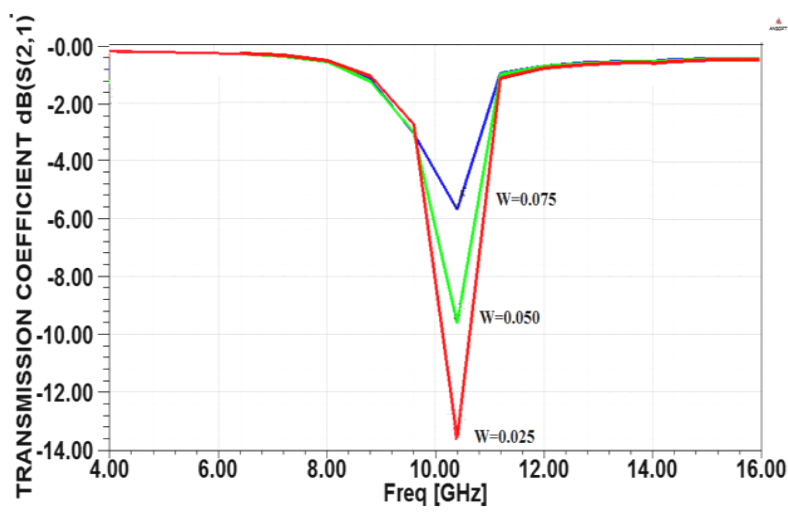

Figure 5: Transmission coefficient $\left(\mathrm{S}_{21}\right)$ of the sensor based on periodic CSRR for $75 \mu \mathrm{m}, 50 \mu \mathrm{m}$ and $25 \mu \mathrm{m}$ crack widths 
Table 2. Transmissiom minimum frequency

\begin{tabular}{|l|c|c|}
\hline $\begin{array}{l}\text { Dimension } \\
\text { of Crack } \\
\text { (Width and } \\
\text { Height) }\end{array}$ & $\begin{array}{c}\text { Single CSRR } \\
\text { (Transmission } \\
\text { minimum } \\
\text { Frequency) }\end{array}$ & $\begin{array}{c}\text { Periodic CSRR } \\
\text { (Transmission } \\
\text { minimum } \\
\text { Frequency) }\end{array}$ \\
\hline $75 \mu \mathrm{m}, 1 \mathrm{~mm}$ & $4.8682 \mathrm{GHz}$ & $10.4000 \mathrm{GHz}$ \\
\hline $50 \mu \mathrm{m}, 1 \mathrm{~mm}$ & $4.8545 \mathrm{GHz}$ & $10.4000 \mathrm{GHz}$ \\
\hline $25 \mu \mathrm{m}, 1 \mathrm{~mm}$ & $4.8818 \mathrm{GHz}$ & $10.4000 \mathrm{GHz}$ \\
\hline
\end{tabular}

\section{CONCLUSION}

This paper describes the detection of small cracks in conductive surfaces by employing the periodic structure of CSRR. A microstrip line feed comprising CSRRs is used as the sensor to detect cracks in metal surfaces covered or concealed by a dielectric layer. The proposed periodic structure of CSRRs improves the sensitivity of sensor and leading to a high sensitivity in the detection of anomalies like cracks. The proposed sensor operates around $10 \mathrm{GHz}$ for a crack width of $25 \mu \mathrm{m}, 50 \mu \mathrm{m}$, and $75 \mu \mathrm{m}$ respectively. Thus sensor exhibits higher sensitivity then all the other techniques employed previously for the purpose of crack detection and its fabrication is not expensive as the dimensions of CSRRs' are optimized in order to fit into the same size of the substrate. It can be concluded that this new sensor is both cost and time effective. Further, detection of even smaller cracks such as in nanometer frequency range can be accomplished with this novel sensor by increasing the number of resonators.

\section{REFERENCES}

[1] J. Kerouedan, P. Qufflecv, Talbot, C. Quendo, S. Blasi, and A. Brun, "Detection of micro-cracks on metal surfaces using near-field microwave dual-behavior resonator filters," Measurement Science and Technology, Vol. 19, No.10, pp. 105701, 2008.

[2] Chin-Yung Yeh and Reza Zoughi, "A novel microwave method for detection of long surface cracks in metals. Instrumentation and Measurement," IEEE Transactions on, Vol. 43, No.5, pp.719 -725, Oct 1994.

[3] R. Zoughi, S.I. Ganchev, and C. Huber, "Measurement parameter optimization for surface crack detection in metals using an open-ended waveguide probe," Instrumentation and Measurement Technology Conference, 1996. IMTC-96. Conference Proceedings.
'Quality Measurements: The Indispensable Bridge between Theory and Reality", IEEE, Vol. 2, pp. 13911394, 1996.

[4] R. Zoughi and S. Kharkovsky, "Microwave and millimeter wave sensors for crack detection," Fatigue \& Fracture of Engineering Materials \& Structures, Vol. 31, No. 8, pp. 695-713, 2008.

[5] A. M. Albishi, M. S. Boybay, and O. M. Ramahi, "Complementary split-ring resonator for crack detection in metallic surfaces," IEEE Microw. WirelessCompon. Lett., Vol.22, No.6, pp.330-332, Jun.2012.

[6] Rakhesh Singh Kshetrimayum, Sridhar Kallapudi and S. S. Karthikeyan, "Stop Band Characteristics for Periodic Patterns of CSRRs in the Ground Plane and its Applications in Harmonic Suppression of Band Pass Filters," International Journal of Microwave and Optical Technology, Vol. 3, No. 2, April 2008.

[7] Bing Hu, Zhao Ren, Muhammed S. Boybay and Omar M. Ramahi, IEEE Transactions on Microwave Theory and Techniques, Vol. 62, No. 4, April 2014.

[8] H. G. Booker, "Slot aerials and their relation to complementary wire serials (Babinet's principle)," J. Inst. Elect. Eng., pt. III-A, Vol. 93, No.4, pp. 620-626, March /May 1946.

[9] Rakhesh Singh Kshetrimayum, and S. S. Karthikeyan, "A parametric study on the stopband characteristics of CSRRs, Int. J. of Recent Trends in Engineering and Technology,” Vol. 1, No. 3, Nov 2009.

[10] Rajni, Gursharan Kaur, Amanpreet Kaur and Anupma Marwaha, "Investigation on Frequency Analysis of Metamaterial Structure," International conference Electronics Design Innovtion and Technologies, EDIT2015, Vol. 2, pp. 166-168, April 2015.

[11] Vidyalakshmi, M. R. and S. Raghavan, "Comparison of optimization techniques for square split ring resonator", International Journal of Microwave and Optical Technology,” Vol. 5, No. 5, Sep. 2010.

[12] B.I. Wu, W. Wang, J. Pacheco, X. Chen, T. Grzegorczyk, and J. A. Kong, "A study of using metamaterials as antenna substrate to enhance gain," Progress in Electromagnetics Research, Vol. 51, pp. 295 $328,2005$. 